Revista Brasileira de Agricultura Irrigada v.7, nº 3, p. 213 - 223 , 2013

ISSN 1982-7679 (On-line)

Fortaleza, CE, INOVAGRI - http://www.inovagri.org.br

DOI: $10.7127 /$ rbai.v7n300019

Protocolo 019.13 - 13/05/2013 Aprovado em 28/06/2013

\title{
AVALIAÇÃO DA QUALIDADE DA ÁGUA DO DISTRITO DE IRRIGAÇÃO TABULEIROS LITORÂNEOS DO PIAUÍ - DITALPI
}

Luis Gonzaga Medeiros de Figueredo Júnior ${ }^{1}$, Jucielle Rocha Ferreira ${ }^{2}$, Carlos Newdmar Vieira Fernandes ${ }^{3}$, Alex Carvalho Andrade ${ }^{4}$, Benito Moreira de Azevedo ${ }^{5}$, Kleiton Rocha Saraiva $^{6}$

\section{RESUMO}

Em agricultura irrigada, o manejo adequado da água contribui para o sucesso do sistema produtivo, devido o teor salino das águas de irrigação, associado às altas temperaturas e intensa evaporação ocasionarem a salinização dos solos, reduzindo o crescimento e a produtividade das culturas. Nesse contexto, o trabalho teve como objetivo avaliar a variabilidade temporal dos sais na água de irrigação e seus efeitos no solo do Distrito de Irrigação Tabuleiros Litorâneos do Piauí - DITALPI, com vistas a diagnosticar eventuais problemas e monitorar a qualidade da água na área. Foram analisados os principais parâmetros físico-químicos que definem a qualidade da água para irrigação: $\mathrm{pH}$, condutividade elétrica, razão de adsorção de sódio, $\mathrm{Ca}^{2}{ }^{+}, \mathrm{Mg}^{2+}, \mathrm{Na}^{+}, \mathrm{K}^{+}, \mathrm{Cl}^{-}, \mathrm{CO}_{3}{ }^{2-}$ e $\mathrm{HCO}_{3}{ }^{-}$, enquanto no solo foram determinados: $\mathrm{pH}, \mathrm{Ca}^{2+}, \mathrm{Mg}^{2+}, \mathrm{Na}^{+} \mathrm{e} \mathrm{Al}^{3+}$, de acordo com os padrões da Organização das Nações Unidas para a Alimentação e a Agricultura (FAO). As coletas foram realizadas no período de outubro/2005 a julho/2007, abrangendo tanto o período chuvoso quanto o período de estiagem, em cinco pontos que abrangem desde o canal de aproximação do Rio Parnaíba, até os lotes situados no final da área de produção. Os resultados indicam que os valores obtidos atendem aos padrões exigidos pelas normas vigentes para uso da água na irrigação.

Palavras-chave: Salinidade do solo, condutividade elétrica, manejo da água.

\section{WATER QUALITY EVALUATION ON THE DISTRITO DE IRRIGAÇÂO TABULEIROS LITORÂNEOS DO PIAUÍ - DITALPI}

\footnotetext{
${ }^{1}$ Doutor em Irrigação e Drenagem. Professor Adjunto, Universidade Estadual do Piauí, Parnaíba-PI, Fone/Fax: (86) 33211825. E-mail: figueredojunior@yahoo.com.br

${ }^{2}$ Mestre em Agronomia/Universidade Federal da Paraíba. Cidade Universitária - João Pessoa - PB. E-mail: jucieller@yahoo.com.br

${ }^{3}$ Doutorando em Engenharia Agrícola, Depto. de Engenharia Agrícola, Bloco 804 UFC/Fortaleza - CE. E-mail: newdmar@yahoo.com.br

${ }^{4}$ Doutor em Zootecnia. Professor Adjunto, Universidade Estadual do Piauí, Parnaíba-PI. E-mail: acandrade4@hotmail.com

${ }^{5}$ Doutor em Irrigação e Drenagem. Professor Associado, Universidade Federal do Ceará, Fortaleza-CE. E-mail: benitoazevedo@hotmail.com

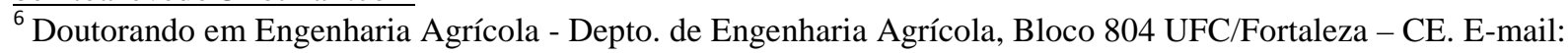
kleitonagro@bol.com.br
} 


\section{AVALIAÇÃO DA QUALIDADE DA ÁGUA DO DISTRITO DE IRRIGAÇÃO TABULEIROS LITORÂNEOS DO PIAUÍ - DITALPI}

\section{ABSTRACT}

Irrigation management has been the focus of great interest to those studying irrigated agriculture. The presence of salts in the irrigation water, for instance, associated with higher temperatures and intense evaporation can cause soil salinization, reducing growth and crop yield. This study was aimed at evaluating the temporal variability of salts in the irrigation water and its effects on the soil of the Distrito de Irrigação Tabuleiros Litorâneos do Piauí (DITALPI). That was done in order to diagnose any problems and monitor the water quality in the area. We analyzed the main physico-chemical parameters defining irrigation water quality: $\mathrm{pH}$, electrical conductivity, plus the adsorption rates of $\mathrm{Na}^{+}, \mathrm{Ca}^{2+}, \mathrm{Mg}^{2+}, \mathrm{K}^{+}, \mathrm{Cl}^{-}$, $\mathrm{CO}_{3}{ }^{2-}$ and $\mathrm{HCO}_{3}{ }^{-}$. In the soil, we determined: $\mathrm{pH}, \mathrm{Ca}^{2+}, \mathrm{Mg}^{2+}, \mathrm{Na}^{+}$and $\mathrm{Al}^{3+}$, by the standards of the United Nations Food and Agriculture Organization (FAO). Sampling was carried out from October 2005 to July 2007, covering both the rainy and the dry season, at five points ranging from the approach channel of the Parnaíba River up lots located at the end of the production area. The results indicated that the obtained values met the current standards required for irrigation use.

Keywords: Soil salinity, electrical conductivity, water management.

\section{INTRODUÇÃO}

Nas regiões semiáridas, como em grande parte da região Nordeste do Brasil, as condições climáticas são caracterizadas por altas temperaturas, precipitações insuficientes e frequente irregularidade da chuva, contribuindo substancialmente para a ocorrência de déficits hídricos durante a maior parte do ano, o que aponta para a importância da adoção da prática de irrigação, objetivando uma menor dependência das condições climáticas e mantendo a propriedade com renda durante a maior parte do ano (BONFIM et al., 2004; CAVALCANTE; CAVALCANTE, 2006; MEDEIROS et al., 2010).

$O$ sucesso na agricultura irrigada depende da disponibilidade da água em quantidade e em qualidade, entretanto o aspecto qualidade está mais diretamente envolvido, em função da concentração salina de grande parte dos recursos hídricos, dos volumes disponíveis, da grande demanda de água para a agricultura em relação às outras atividades e da sensibilidade da grande maioria das plantas de interesse econômico (FIGUEIRÊDO et al., 2009; CAVALCANTE et al., 2012).

Pode-se definir a qualidade da água por suas características físicas, químicas ou biológicas, sendo que na sua avaliação para a irrigação deve ser avaliada principalmente sob três aspectos considerados importantes na determinação da qualidade agronômica, sendo eles: salinidade, sodicidade e toxidade de íons (ALMEIDA, 2010). De acordo com Shalhevete Kamburov (1976), a composição e qualidade das águas destinadas à irrigação dependem da zona climática, da fonte da água, do trajeto percorrido, da época do ano e da geologia da região.

Os sais presentes nas águas têm sua origem na intemperização das rochas e dos solos, pela dissolução lenta do calcário e de outros minerais, que são levados pelas águas de irrigação e se depositam no solo, acumulando à medida que a água evapora ou é consumida pelas culturas (RHOADES et al., 1992).

A despeito dos benefícios da irrigação, é comum a intensificação dos cultivos com o uso ineficiente desta prática, o que na maioria das vezes resulta na perda da qualidade do solo e abandono das áreas agrícolas. Nesse cenário, atenção especial deve estar voltada para o manejo do solo, das culturas e da água de irrigação, especialmente em áreas agrícolas inseridas em perímetros irrigados, visando 


\section{AVALIAÇÃO DA QUALIDADE DA ÁGUA DO DISTRITO DE IRRIGAÇÃO TABULEIROS LITORÂNEOS DO PIAUÍ - DITALPI}

evitar a degradação do solo e, por consequência, a diminuição da produtividade das culturas (LYRA et al.,1995; MICHELON et al., 2007). Portanto, o uso eficiente do solo e da água em perímetros irrigados configura-se como único meio capaz de manter a sustentabilidade dessas áreas (SANTOS; RIBEIRO, 2000).

No caso de solos com baixo teor de argila, o acúmulo de sais solúveis na solução do solo normalmente não ocorre próximo à superfície, contudo pode concentrar-se em camadas intermediárias do perfil, devido à lixiviação (XAVIER et al., 2012). Os resultados obtidos por Silva et al. (2011) demonstram que a salinidade em Neossolo Quartzarênico apresentou tendência a uma maior concentração de sais na profundidade de $40 \mathrm{~cm}$, afetando as culturas com sistema radicular mais profundo. Esse comportamento é explicado, segundo os autores, pelo maior conteúdo de areia nesse tipo de solo, fazendo com que os sais sejam lixiviados no perfil, implicando em um potencial risco de salinização.

De acordo com Santos (2000), embora a fonte principal e mais direta de todos os sais encontrados no solo seja a intemperização das rochas, raros são os exemplos em que a mesma tenha provocado, de forma direta, problemas de salinidade no solo, de forma que, normalmente tais problemas são associados à água de irrigação e à presença de lençol freático elevado. Garcia et al. (2007) afirmam que a utilização de águas salinas sem uma fração de lixiviação adequada, pode provocar a salinização dos solos, reduzindo o crescimento, 0 desenvolvimento das plantas e os teores de macronutrientes catiônicos.

O acompanhamento das alterações da qualidade da água faz parte do gerenciamento dos recursos hídricos e controle ambiental de forma a impedir que problemas decorrentes da poluição da água venham a comprometer seu aproveitamento múltiplo e integrado, e de forma a colaborar para a minimização dos impactos negativos ao meio ambiente (BRAGA et al., 2006).

Como consequência da negligencia de avaliação da qualidade da água, a irrigação poderá produzir efeitos indesejáveis na condução de uma cultura ou servir como veículo para contaminação da população (MANTOVANI et al., 2009). Assim, para minimizar os problemas da utilização deágua de irrigação, é necessário que exista um planejamentoe monitoramento adequados para avaliação da sua qualidade (REIS et al., 2011).

O monitoramento da qualidade da água destinada à irrigação, normalmente é feito com a finalidade de identificar e prevenir contra problemas de salinidade, sodicidade, toxicidade, poluição; por isso, deve ser considerado como parte de um programa de utilização racional dos recursos hídricos na agricultura da região (AYERS; WESTCOT, 1999; GHEYI, et al., 2010). A qualidade da água utilizada nos Tabuleiros Litorâneos do Piauí, contudo, não é monitorada sistematicamente, isso evidencia uma carência de estudos técnicos e científicos destinados à eficiência de manejo das águas para fins de irrigação. Ao considerar a expressividade econômica, social e científica do monitoramento da água, as informações deverão contribuir para adoção de medidas preventivas ou minimizadoras, acerca dos impactos ambientais e gerenciamento integrado dos recursos hídricos na região. Nesse sentido, contribuirá como suporte para tomadas de decisões para a sustentabilidade da conservação do solo e da água.

Diante do exposto a realização do presente trabalho teve como objetivo avaliar a variabilidade temporal da concentração de sais na água de irrigação e seus efeitos sobre os solos irrigados do Distrito de Irrigação Tabuleiros Litorâneos do Piauí - DITALPI, com vistas a 


\section{AVALIAÇÃO DA QUALIDADE DA ÁGUA DO DISTRITO DE IRRIGAÇÃO TABULEIROS LITORÂNEOS DO PIAUÍ - DITALPI}

diagnosticar eventuais problemas e monitorar a qualidade da água.

\section{MATERIAL E MÉTODOS}

O estudo foi realizado no perímetro irrigado Tabuleiros Litorâneos do Piauí, situado no município de Parnaíba - PI ( $2^{\circ} 55^{\prime}$ latitude Sul, 41 ${ }^{\circ} 50$ ' longitude Oeste, $40 \mathrm{~m}$ de altitude). O clima da região, de acordo com a classificação de Köppen, é do tipo Aw', tropical chuvoso, com precipitação média anual de aproximadamente $1.000 \mathrm{~mm}$ (concentrada no período de verão-outono) e umidade relativa do ar em torno de $75 \%$ (BASTOS et al., 2000). O solo utilizado foi classificado como Neossolo Quartzarênico Órtico típico.

A qualidade das águas superficiais do Distrito de Irrigação Tabuleiros Litorâneos do Piaú́ - DITALPI, proveniente do Rio Parnaíba, foi monitorada com base nas análises de amostras de 1,0 L, coletadas na profundidade $0-0,20 \mathrm{~m}$, diretamente no canal de irrigação em 05 (cinco) pontos estratégicos identificados na área de estudo (Tabela 1), no período de outubro de 2005 a julho de 2007, totalizando 08 (oito) coletas, abrangendo tanto o período chuvoso (janeiro a maio) quanto o período de estiagem (junho a dezembro), realizadas em: out/05; dez/05; fev/06; abr/06; dez/06; fev/07; mai/07; jul/07.

Tabela 1. Identificação dos pontos selecionados para coleta de água.

\begin{tabular}{cc}
\hline Locais selecionados & Identificação dos pontos de coleta \\
\hline EBP $^{1}$ & $01 \quad$ - antes da captação principal \\
EBV $^{2} 04$ & $02 \quad$ - captação da EBV 04 \\
EBV 05 & $03 \quad$ - captação da EBV 05 \\
EBV 06 & $04 \quad$ - captação da EBV 06 \\
EBV 08 & $05 \quad$ - LP 08 - Lote 65 \\
\hline
\end{tabular}

${ }^{1}$ Estação de bombeamento principal; ${ }^{2}$ Estação de bombeamento volumétrica.

Com o objetivo de verificar os riscos de salinização do solo, foram realizadas análises de solo em cinco áreas do perímetro irrigado (Tabela 2) no período de dezembro de 2006 a outubro de 2007. As amostras foram retiradas na profundidade de $20 \mathrm{~cm}$.

Tabela 2. Identificação dos pontos selecionados para coleta de solo.

\begin{tabular}{ccc}
\hline Pontos de coleta & Identificação dos pontos de coleta & Culturas presentes \\
\hline EBV 03 & $01-$ LP $^{1} .03 . \mathrm{D}-02$ & Feijão e Melancia \\
EBV 04 & $02-$ LP. 04. E -35 & Coco \\
EBV 05 & $03-$ LP. 05. D -32 & Acerola \\
EBV 07 & $04-$ LP. 07. D -47 & Goiaba \\
EBV 08 & $05-$ LP. 08 -65 & Caju
\end{tabular}

${ }^{1}$ Lote particular.

As análises dos diversos parâmetros da água e do solo para fins de irrigação foram realizadas nos laboratórios da
Embrapa Meio Norte, conforme procedimento descrito por Machado et al. (1998) e Moraes (2001), sendo observadas 


\section{AVALIAÇÃO DA QUALIDADE DA ÁGUA DO DISTRITO DE IRRIGAÇÃO TABULEIROS LITORÂNEOS DO PIAUÍ - DITALPI}

as características que determinam a qualidade das águas em relação à cultura, manejo e efeitos no solo. As determinações na água contemplaram: $\mathrm{pH}$, condutividade elétrica (CE), razão de adsorção de sódio (RAS), cálcio $\left(\mathrm{Ca}^{2+}\right)$, magnésio $\left(\mathrm{Mg}^{2+}\right)$,

\section{RESULTADOS E DISCUSSÃO}

Na Tabela 3 está apresentado o resumo das análises físico-químicas realizadas na água de irrigação contendo os valores médios para cada variável, obtidos a partir dos cinco pontos amostrados. Os resultados indicam que exceto para bicarbonatos $\left(\mathrm{HCO}_{3}{ }^{-}\right)$, os valores registrados situam-se na faixa considerada normal para uso na irrigação, durante 0 período analisado. Isso mostra que, durante o período de monitoramento da água de sódio $\left(\mathrm{Na}^{+}\right)$, potássio $\left(\mathrm{K}^{+}\right)$, cloretos $\left(\mathrm{Cl}^{-}\right)$, carbonatos $\left(\mathrm{CO}_{3}{ }^{2-}\right)$ e bicarbonatos $\left(\mathrm{HCO}_{3}{ }^{-}\right)$, enquanto no solo foram determinados: $\mathrm{pH}$, cálcio $\left(\mathrm{Ca}^{2}\right)$, magnésio $\left(\mathrm{Mg}^{2+}\right)$, sódio $\left(\mathrm{Na}^{+}\right)$, alumínio $\left(\mathrm{Al}^{3+}\right)$.

irrigação não houve deposição de elementos em quantidades que pudessem elevar os níveis de sais da água, o que permite dessa forma, enquadrá-la como uma água de qualidade boa para irrigação, com risco desprezível de salinização do solo a curto e médio prazo. Esses resultados foram comparados com as diretrizes propostas por Ayers e Westcot (1999) para interpretação da qualidade da água com fins agrícola.

Tabela 3. Resumo da análise de água do DITALPI. Valores médios do período 2005/2007.

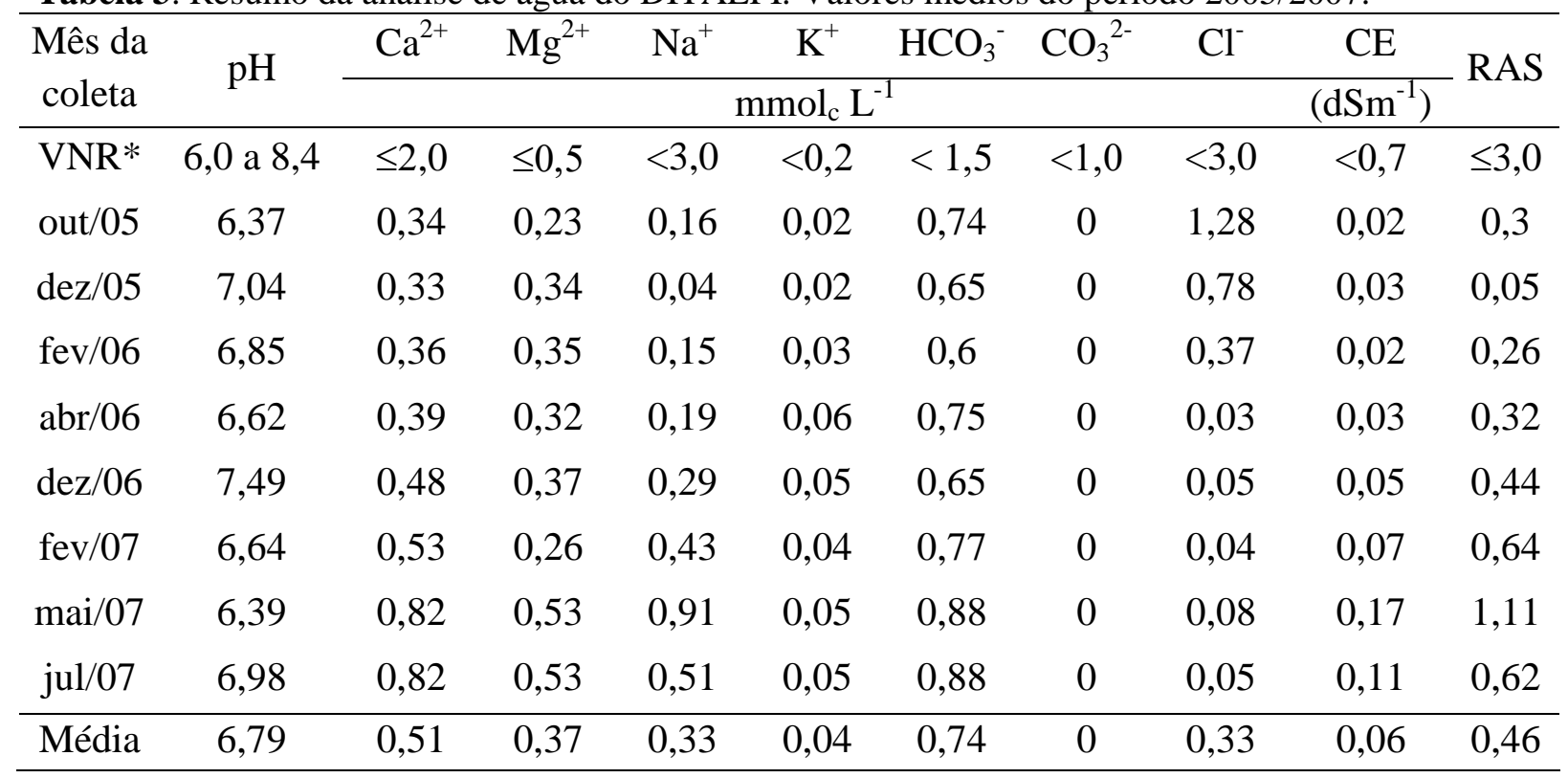

* Valores normais de referência (AYERS; WESTCOT, 1999).

De acordo com a classificação baseada na condutividade elétrica (CE) e na Razão de Adsorção de Sódio (RAS), proposta pelo U.S. Salinity Laboratory STAFF, bastante difundida na literatura (MAAS, 1986; BERNARDO et al., 2006), a água do DITALPI pode ser classificada como $\mathrm{C}_{1} \mathrm{~S}_{1}$, isto é, apresenta baixo perigo de salinização e sodificação do solo, não resultando em restrição quanto aos sais para uso na irrigação da maioria das culturas de valor econômico.

Quanto à análise de solo, os resultados obtidos (Tabela 4) indicam que durante o período de avaliação, não houve acumulação de nenhum íon avaliado em nível que comprometa o crescimento das plantas, onde os valores encontrados 


\section{AVALIAÇÃO DA QUALIDADE DA ÁGUA DO DISTRITO DE IRRIGAÇÃO TABULEIROS LITORÂNEOS DO PIAUÍ - DITALPI}

através de análises físico-químicas apontaram níveis abaixo do grau de restrição para uso na agricultura, o que não representa risco para utilização do solo nas condições encontradas.

Tabela 4. Resumo da análise de solo do DITALPI. Valores médios do período 2006/2007.

\begin{tabular}{ccccccc}
\hline \multirow{2}{*}{ Amostra } & \multirow{2}{*}{ Cultura } & $\mathrm{pH}$ & \multicolumn{4}{c}{$\mathrm{Ca}^{+2}$} \\
\cline { 4 - 6 } & Pousio & 4,63 & 2,61 & 0,80 & 0,05 & 0,00 \\
2 & Coco & 5,75 & 2,15 & 0,59 & 0,05 & 0,02 \\
3 & Acerola & 6,20 & 1,70 & 0,50 & 0,05 & 0,00 \\
4 & Goiaba & 5,85 & 1,47 & 1,30 & 0,07 & 0,01 \\
5 & Caju & 6,40 & 1,97 & 1,12 & 0,04 & 0,00 \\
\hline
\end{tabular}

Valores não compatíveis com o grau de tolerância das plantas podem ser prejudiciais ao seu desenvolvimento, pois segundo Ayers e Westcot (1999), os sais são adicionados na zona radicular do solo junto às águas de irrigação, aumentando a concentração à medida que as culturas consomem por evapotranspiração grande parte da água armazenada, ficando quase todos os sais em volumes cada vez menores da água remanescente no solo. Essa medida aumenta a concentração dos sais do solo, ocorrendo uma redução na disponibilidade de solução do solo a tal ponto que afetam os rendimentos da planta, mesmo havendo quantidades razoáveis de água armazenada no solo.

Quanto ao $\mathrm{pH}$, os valores médios determinados (Tabela 4), em algumas localidades estão abaixo, na faixa suficiente para uso do solo na agricultura. Esses resultados concordam com a amplitude considerada normal para irrigação segundo critérios internacionais para a interpretação da qualidade da água (DIAS, 2004; HUGHES; HANAN, 1978).

As obstruções de emissores foram definidas em três tipos por Rodrigo Lopez et al. (1992), sendo: (i) as físicas, que são provocadas por materiais orgânicos e/ou minerais que se encontram em suspensão na água, ou mesmo que são transportados por ela, se aderindo aos emissores e interrompendo a livre passagem de água; (ii) as químicas, que são aquelas desenvolvidas por meio de precipitações de substâncias dissolvidas na água, tais como sulfatos e bicarbonatos, e (iii) as biológicas, que são ocasionadas por organismos vivos ou por partes desses incorporados na água de irrigação.

Dentre os problemas de ordem química que afetam negativamente a uniformidade de distribuição de água, alguns estudos apontam que quando a diferença entre os valores da soma de cálcio mais magnésio e de bicarbonato mais carbonato, ou seja, $(\mathrm{Ca} 2++\mathrm{Mg} 2+)-$ (HCO3- + CO32-), for negativa, poderá haver precipitação de cálcio resultando na obstrução dos emissores (DIAS et al., 2004; RAVINA et al., 1992; SILVA JÚNIOR \& MEDEIROS, 2007). Por outro lado, no presente caso, apenas em dois, dos oito períodos de coleta, foi observada tal situação. Dessa forma, os casos de obstrução observados, possivelmente, podem ter sidos ocasionados principalmente pelos problemas de natureza física.

Conforme relatos de produtores locais, os maiores problemas relacionados à qualidade da água são de ordem física, ocasionando entupimentos nos emissores dos sistemas de irrigação, provavelmente devido à deposição de sedimentos e presença de sólidos em suspensão na água do canal. Para contornar esse problema a administração do DITALPI realizou a limpeza do canal de irrigação, com o 


\section{AVALIAÇÃO DA QUALIDADE DA ÁGUA DO DISTRITO DE IRRIGAÇÃo \\ TABULEIROS LITORÂNEOS DO PIAUÍ - DITALPI}

esvaziamento total e a retirada de sedimentos e impurezas presentes em seu curso em 25/05/06, durante a vigência deste trabalho, reduzindo assim os frequentes entupimentos dos emissores.

Analisando-se o conteúdo de $\mathrm{Na}^{+}$e $\mathrm{Ca}^{2+}+\mathrm{Mg}^{2+}$ das águas (Figuras 1 e 2, respectivamente) durante o período de outubro/2005 a julho/2007, observa-se uma tendência de aumento dos valores de ambos os parâmetros até o mês de maio/07, havendo a partir de então, redução do valor de $\mathrm{Na}^{+}$e estabilização dos valores de $\mathrm{Ca}^{+}+\mathrm{Mg}^{+}$. Contudo, o aumento na quantidade desses sais na água não foi suficiente para ultrapassar a classe $\mathrm{C}_{1} \mathrm{~S}_{1}$, mantendo-se com baixo perigo de salinização e de sodificação do solo, de acordo com a classificação proposta pelo laboratório U.S. Salinity Laboratory STAFF - U.S.D.A.

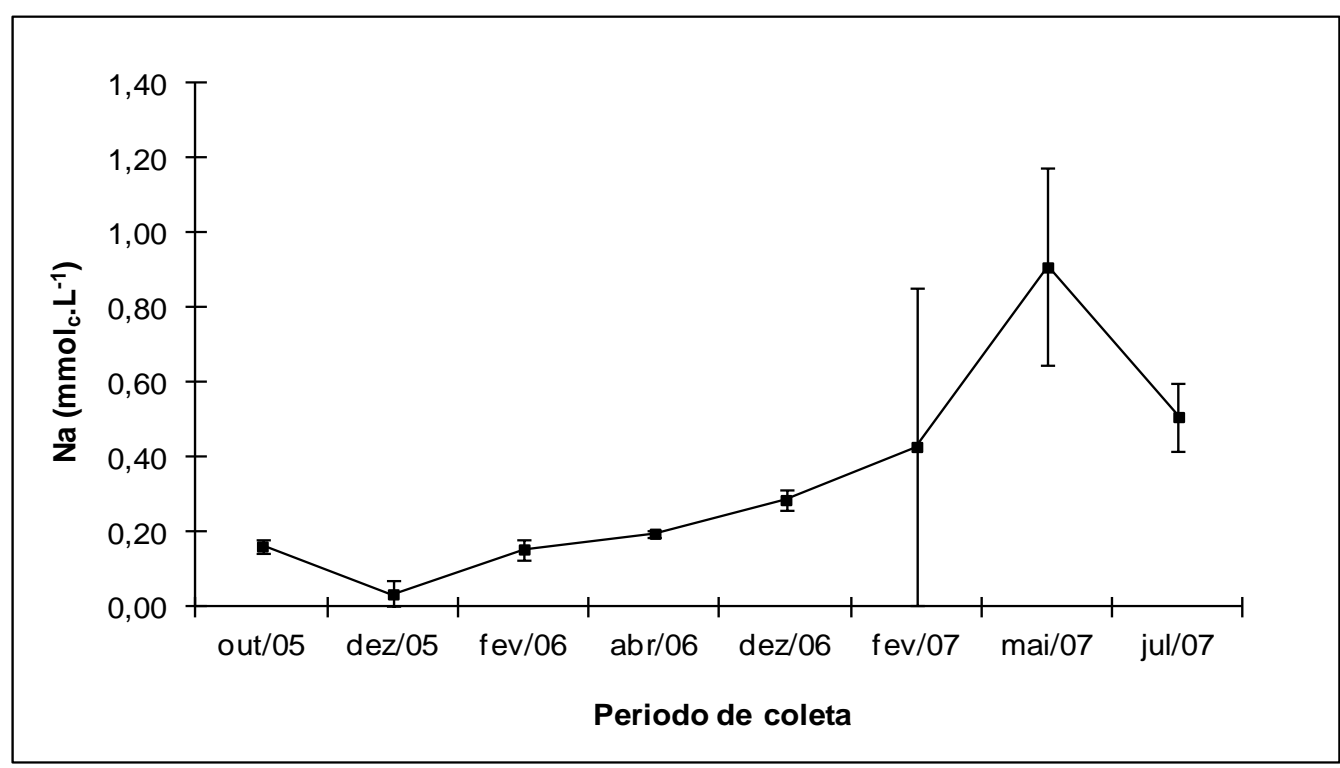

Figura 1. Variação no conteúdo de $\mathrm{Na}^{+}$na água do DITALPI, no período de outubro/05 a julho/2007.

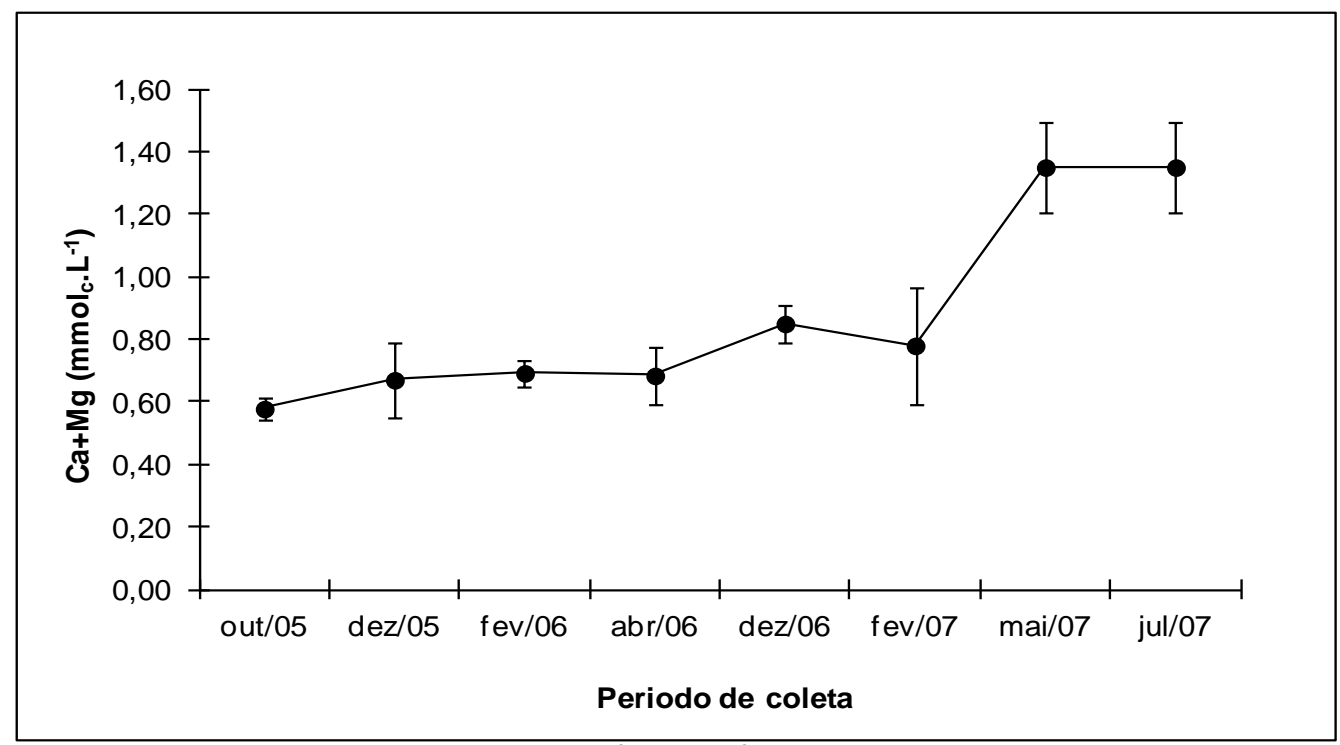

Figura 2. Variação no conteúdo de $\mathrm{Ca}^{2+}+\mathrm{Mg}^{2+}$ na água do DITALPI, no período de outubro/05 a julho/2007. 


\section{AVALIAÇÃO DA QUALIDADE DA ÁGUA DO DISTRITO DE IRRIGAÇÃO TABULEIROS LITORÂNEOS DO PIAUÍ - DITALPI}

A razão de adsorção de sódio (RAS) apresentou variação semelhante à de $\mathrm{Na}^{+}$, em virtude do conteúdo desse íon ter maior peso no cálculo da RAS (Figura 3). Ressalta-se a importância da continuidade do monitoramento da qualidade da água neste perímetro irrigado, como forma de subsidiar a tomada de decisão com relação ao manejo da água e do solo em médio e longo prazo.

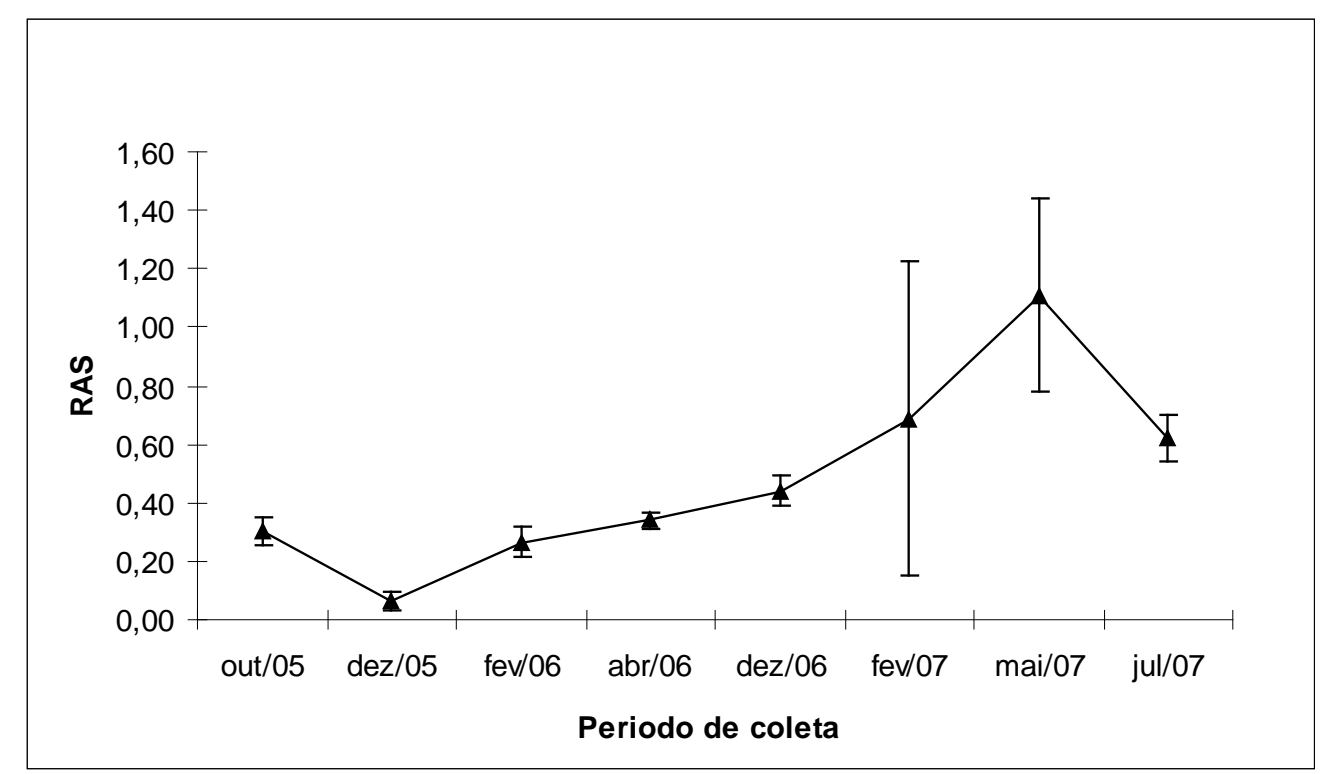

Figura 3. Variação da razão de adsorção de sódio (RAS) na água do DITALPI, no período de outubro/05 a julho/2007.

Finalmente, pode-se inferir que a água de irrigação não vem afetando negativamente a qualidade química do solo na área estudada. As águas são adequadas à irrigação das mais variadas culturas, inclusive as fruteiras tradicionalmente cultivadas e não evidenciam riscos à salinidade (COSTA; PACOVA, 2003; MEDEIROS et al., 2010; CAVALCANTE et al., 2012). Entretanto, ressalta-se a

\section{CONCLUSÃO}

A água utilizada para irrigação, no perímetro irrigado Tabuleiros Litorâneos do Piauí é de boa qualidade e não oferece perigos de salinização, de sodificação ao

\section{REFERÊNCIAS BIBLIOGRÁFICAS}

ALMEIDA, O. A. Qualidade da água de irrigação. Cruz das Almas. Embrapa: Mandioca e Fruticultura, 2010. 234p. necessidade de avaliação sistemática, simultaneamente, da água e do solo, por um período mais longo, como meta de prevenção do solo contra os riscos da salinidade às fruteiras em cultivo que, na maioria são de moderadamente sensíveis a tolerantes à ação da salinidade (ARAÚJO FILHO et al., 1995; AYERS; WESTCOT, 1999; FERREIRA NETO et al., 2002).

solo, e nem de toxicidade à maioria das plantas cultivadas de interesse econômico, inclusive as exploradas no local investigado.
ARAÚJO FILHO, J.B.; GHEYI, H.R.; AZEVEDO, N.C. Tolerância da bananeira à salinidade em fase inicial de 


\section{AVALIAÇÃO DA QUALIDADE DA ÁGUA DO DISTRITO DE IRRIGAÇÃO TABULEIROS LITORÂNEOS DO PIAUÍ - DITALPI}

desenvolvimento. Pesquisa agropecuária brasileira, v. 30, n. 07, p. 989-997, 1995.

AYERS, R. S.; WESTCOT, D.W. A Qualidade da Água na Agricultura. Tradução de H.R. GHEYI, J. F. DE MEDEIROS, F. A. V. DAMASCENO. Campina Grande: UFPB, 1999. 153p.

BASTOS, E.A. NUNES, B.H.; ANDRADE JUNIOR, A.S. Dados agrometeorológicos para o município de Parnaíba, PI. Teresina: EMBRAPA, 2000. 27p. (Documentos, 45).

BERNARDO, S.; SOARES, A. A.; MANTOVANI, E. C. Manual de irrigação, 8.ed. Viçosa: UFV, 2006. 625p.

BOMFIM, G. V. DO; AZEVEDO, B. M. DE; VIANA, T. V. DE A.; BORGES, R. L. M.; OLIVEIRA, J. J. G. Calibração de um lisímetro de pesagem após dois anos de utilização. Revista Ciência Agronômica, v. 35, Número Especial, p. 284-290, 2004.

BRAGA, B.; PORTO, M.; TUCCI, C.E.M. Monitoramento da Quantidade e Qualidade das Águas. In: Águas Doces no Brasil: capital ecológico, uso e conservação. Ed. $3^{\text {a }}$, São Paulo. p. 145160. 2006.

CAVALCANTE, L. F.; CAVALCANTE, I. H. L. Uso de água salina na agricultura. In: Cavalcante, L. F.; Lima, E. M (Eds). Algumas frutíferas tropicais e a salinidade. 1 ed. Jaboticabal: FUNEP, 2006. cap., I, p.1-17.

COSTA, A.F.S.; PACOVA, B.E. Botânica e Variedades.. In: COSTA, A.F.S.; COSTA, A.N. Tecnologias para produção de goiabas. Vitória, ES: INCAPER, 2003. p.27-56.

DIAS, N.S. Manejo da fertirrigação e controle da salinidade em solo cultivado com melão rendilhado sob ambiente protegido. Piracicaba: ESALQ, 2004. 110p. (Tese Doutorado)

DIAS, N. da S.; OLIVEIRA, M. V. A. M. de; COELHO, R. D. Resistência de diferentes tipos de tubogotejadores ao entupimento por precipitação química de cálcio. Revista Irriga, v. 09, n. 02, p.115125, 2004.

FERREIRA NETO, M. GHEYI, H.R.; HOLANDA, J.S.; MEDEIROS, J.F.; FERNANDES, P.D. Qualidade do fruto verde de coqueiro em função da irrigação com água salina. Revista brasileira de engenharia agrícola e ambiental, v.6, n. 01A, 2002.

FIGUEIRÊDO, V. B. MEDEIROS, J. F. ZOCOLER, J. L. SOBRINHO, J. S.Evapotranspiração da cultura da melancia irrigada com água de diferentes salinidades. Engenharia Agrícola, Jaboticabal, v. 29, n. 02, p.231-240, 2009.

GARCIA, G. O.; FERREIRA, P. A.; MIRANDA, G. V.; NEVES, J. C. L.; MORAES, W. B.; SANTOS, D. B. Teores foliares dos macronutrientes catiônicos e suas relações com sódio em plantas de milho sob estresse salino. Idesia, Arica Chile, v. 25, p. 93-106, 2007.

GHEYI, H. R.; DIAS, N. S.; LACERDA, C. F (Eds). Manejo da salinidade na agricultura: estudos básicos e aplicados. Fortaleza: INCTSal. 2010, 472 p.

HUGHES, H. E.; HANAN, J. J. Effect of salinity in water supplies on greenhouse rose production. Journal of the American Society for Horticultural Science, v. 103, p. 694-699, 1978.

LYRA, M. C. P.; RIBEIRO, M. R.; RODRIGUES, J. J. V. Caracterização de Vertissolos em projetos de irrigação na região do baixo-médio São Francisco: II Propriedades Morfológicas, Físicas e 


\section{AVALIAÇÃO DA QUALIDADE DA ÁGUA DO DISTRITO DE IRRIGAÇÃO TABULEIROS LITORÂNEOS DO PIAUÍ - DITALPI}

Químicas. Revista Brasileira de Ciência do Solo, v. 19, p. 441-448, 1995.

MACHADO, P. L. O. DE; FABRICIO, A. C.; PRIMAVESI, A. C. Água. In: NOGUEIRA, A. R. A.; MACHADO, P. L. O. A.; SANTANA DO CARMO, C. A. F. ed. Manual delaboratório: solo, água, nutrição vegetal, nutrição animal e alimentos. São Carlos: EMBRAPACCPSE, 1998. p. 24-31.

MANTOVANI, E. C.; BERNARDO, S.; PALARETTI, L. F. Irrigação princípios e métodos. 3. Ed. Viçosa: Ed. UFV, 2009. 355 p.

MAAS, E. V. Salt tolerance of crops. Applied Agricultural Research, New York, v. 1, n. 1, p. 12-26, 1986.

MEDEIROS, J. F.; NASCIMENTO, I. B.; GHEYI, H. R. Manejo do solo-águaplanta. In: GHEYI, H. R.; DIAS, N. S.; LACERDA, C. F (Eds). Manejo da salinidade na agricultura: estudos básicos e aplicados. Fortaleza: INCTSal. 2010, parte - IV, p. 279-302.

MORAES, A. J. Manual para a avaliação da qualidade da água. São Carlos: Rima, 2001. 44p.

MICHELON, C.J; CARLESSO, R.; PETRY, M.T.; DAVID, G.; SANTA, C.D. Qualidade física de solos irrigados do Estado do Rio Grande do Sul. Ciência Rural, v. 37, n. 05, p. 1308-1315, 2007.

RAVINA, I.; PAZ, E.; SOFER, Z.; MARCU, A.; SCHISCHA, A.; SAGI, G. Control of clogging in drip irrigation with stored reclaimed wastewater. Irrigation Science, v. 13, p.129-139, 1992.

REIS, C. F. dos.; VILAS BOAS, M. A.; MERCANTE, E.; HERMES, E.; REISDORFER, M.Avaliação da qualidade da água para irrigação em salto do lontra -
PR. Engenharia Ambiental. Espírito Santo do Pinhal, v. 8, n. 1, p. 069-078, 2011.

RHOADES, J. D; KANDIAH, A.; MASHALI, A. M. Uso de águas salinas para produção agrícola. Tradução de H.R. GHEYI, J.R. DE SOUSA, J. E. QUEIROZ. Campina Grande, UFPB, 1992. 117p. (Estudos FAO: Irrigação e Drenagem, 48).

RODRIGO LÓPEZ, R. et al. Riego localizado. Madrid, Mundi-Prensa, 1992. 405p.

SANTOS, J. G. R. dos. A salinidade na agricultura irrigada: teoria e prática. Campina Grande: UFPB, 2000. 171p.

SANTOS, E. E. F.; RIBEIRO, M. R. Influência da irrigação e do cultivo nas propriedades de um Latossolo e um Argissolo da região do submédio São Franciso: Atributos morfológicos e físicos. Revista Brasileira de Ciência do Solo, v. 24, p. 875-884, 2000.

SILVA, J.L.A.; ALVES, S.S.V.; NASCIMENTO, I.B.; SILVA, M.V.T.; MEDEIROS, J.F. Evolução da salinidade em solos representativos do agropólo Mossoró-Assu cultivado com meloeiro com água de deferentes salinidades. ACSA - Agropecuária Científica no SemiÁrido, v. 7, n. 4, p. 26 - 31, 2011.

SILVA JÚNIOR, M.J; MEDEIROS, J.F. Desenvolvimento de obstruções em gotejadores e eficiência do controle usando dois tipos de ácidos. Revista Irriga, v. 12, n. 02, p. 185-191, 2007.

SHALHEVET, J.; KAMBUROV, J. Irrigation and salinity: a world-wide survey. New Delhi, International Commissionon Irrigation and Drainage, 1976. 106p. 


\section{AVALIAÇÃO DA QUALIDADE DA ÁGUA DO DISTRITO DE IRRIGAÇÃO \\ TABULEIROS LITORÂNEOS DO PIAUÍ - DITALPI}

XAVIER, F.A.S, TAVARES, R.C.; químicos de um Neossolo Quartzarênico MARQUES, G.V, RODRIGUES, F.M.; cultivado com coqueiro anão. Revista OLIVEIRA, T.S. Efeitos da irrigação Ciência Agronômica, v. 43, n. 1, p. 55-63, localizada na granulometria e em atributos 2012. 